Boise State University

ScholarWorks

Counselor Education Faculty Publications and

Presentations

6-2019

\title{
The Impact of a Brief, Bullying Bystander Intervention on Internalizing Symptoms: Is Gender a Moderator of Intervention Effects?
}

Diana M. Doumas

Boise State University

Aida Midgett

Boise State University

April D. Watts

Boise State University 


\title{
The Impact of a Brief, Bullying Bystander Intervention on Internalizing Symptoms: Is Gender a Moderator of Intervention Effects?
}

\author{
Diana M. Doumas \\ Boise State University
}

\author{
Aida Midgett \\ Boise State University
}

\author{
April D. Watts \\ Boise State University
}

\begin{abstract}
The purpose of this study was to evaluate the efficacy of a brief, bystander bullying intervention on reducing internalizing symptoms among students $(\mathrm{N}=65)$. Although witnessing bullying is associated with mental health risks, the majority of research on bystander interventions focuses on the impact of these programs on school-wide bullying reduction rather than improved emotional outcomes for those trained to intervene. Results indicated high school students trained in a brief, bystander bullying intervention reported greater decreases in internalizing symptoms from baseline to a 3-month follow-up compared to students in a control group. Further, gender moderated intervention effects such that differences in decreases in internalizing symptoms were significant for females only. Implications for school-based anti-bullying programs for high school students are discussed.
\end{abstract}

Keywords: bullying, bystander, STAC, internalizing symptoms, high school

Bullying is an international problem that has received significant attention from both the media and policymakers over the past decade (Waasdorp, Pas, Zablotsky, Bradshaw, 2017). Although efforts to reduce bullying have resulted in some positive gains in the US (Waasdorp et al., 2017), national survey data indicate 20.8\% of students ages 12-18 continue to report being bullied at school (U.S. Department of Education, 2016). Further, 70.6\% of students in the US report witnessing bullying at school (Bradshaw, Sawyer, \& O’Brennan, 2007). Similarly, statistics from crossnational studies, including countries such as the UK (Rivers et al., 2009), Australia (Rigby \& Jonson, 2006), and South Korea (Song \& Oh, 2017), also indicate most students have observed bullying. The majority of research on bullying, however, focuses on students who are targets or perpetrators, even though a significantly greater number of student report witnessing bullying as bystanders (Rivers, Poteat, Noret, \& Ashurst, 2009). Thus, understanding the impact of bullying on student bystanders is an important area for further investigation.

\section{Witnessing Bullying as a Bystander and Internalizing Symptoms}

Witnessing bullying in adolescence is associated with emotional distress, including helplessness (Rivers \& Noret, 2013), guilt (Hutchinson, 2012), anxiety and depression ( Midgett \& Doumas, in press-b; Rivers et al., 2009). Further, research indicates among high school students, witnessing bullying is a unique predictor of multiple indicators of psychological symptoms, including depression and anxiety, over and above the effects of being a target of bullying (Rivers et al., 2009). Further, compared to high school students who are not involved in bullying, students who witness bullying are also significantly more likely to report symptoms of suicidal ideation (Rivers \& Noret, 2010; 2013). Research also indicates a larger percentage of females report witnessing bullying relative to males (Rivers \& Noret, 2010; Rivers et al., 2009) and female bystanders may experience more distress than males who witness bullying (Brinkman \& Manning, 2016). Thus, the research examining the impact of witnessing bullying suggests that being a bystander is associated with symptoms consistent with internalizing symptoms and these symptoms may be more pronounced for females. 
This is an author-produced, peer-reviewed version of this article. The final, definitive version of this document can be found online at School Psychology International, published by SAGE. Copyright restrictions may apply. doi: 10.1177/0143034319830149

\section{Bystander Behavior}

Although statistics indicate the likelihood of witnessing bullying is much higher than being a target of bullying, the majority of research on the impact of bullying focuses on outcomes for students who are targets (Rivers et al., 2009). Because witnessing bullying is also associated with internalizing symptoms, it is important to identify how bystander behavior is related to psychological correlates of witnessing bullying. Researchers have identified four distinct bystander roles that bystanders assume when observing bullying (Salmivalli, Lagerspet, Björkqvist, Österman, \& Kaukiainen, 1996). Two of these roles, the "assistant" and the "reinforcer," actively support the bullying by joining in with or providing positive feedback to the perpetrators. Students in the third role of "outsider" disengage by leaving the situation or observing from a distance. Finally, students who are "defenders" intervene on behalf of the target of bullying. Of these roles, only the "defender" role is associated with a decrease in bullying behavior (Hawkins, Pepler, \& Craig, 2001; Padgett \& Notar, 2013; Salmivalli, Voeten, \& Poskiparta, 2011; Salmivalli, 2014).

Unfortunately, the majority of students do not intervene in support of the target, with researchers estimating that 20\% to $30 \%$ of students act in ways that support or encourage the bullying (i.e., "assistants" and "reinforcers"), 30\% to $50 \%$ do nothing (i.e., "outsiders"), and only 20\% to 30\% act to defend the target (i.e., "defenders") (O’Connell, Pepler, \& Craig, 1999; Salmivalli \& Voeten, 2004). Research indicates that bystanders may not intervene in bullying situations for several reasons including low levels of personal responsibility (Chen, Chang, \& Cheng, 2016; Choi \& Cho, 2013; Thornberg, Landgren, \& Wilman, 2018), self-efficacy (Chen et al., 2016; Thornberg et al, 2018), and empathy (Choi \& Cho, 2013; Song \& Oh, 2017). Gender differences have also been identified in bystander behavior, suggesting that females are more likely to intervene in bullying situations than males (Jenkins \& Nickerson, 2017; Oh \& Hazler, 2009; Trach, Hymel, Waterhouse, \& Neale, 2010). Researchers have suggested that females may intervene more due to a higher likelihood of noticing bullying events (Jenkins \& Nickerson, 2017), higher reported levels of recognizing the harm of bullying (Thornberg \& Jungert, 2013), higher levels of empathy for students who are victimized (Jenkins \& Nickerson, 2017; Thornberg \& Jungert, 2013), and higher levels of confidence to intervene (Brinkman \& Manning, 2016). Research also indicates that students may not intervene when they witness bullying because they do not know what to do (Forsberg, Samuelsson, \& Thornberg, 2014; Hutchinson, 2012). In order to intervene, bystanders must notice the bullying situation, interpret it as serious, accept responsibility to intervene, and know how to intervene appropriately (Lambe, Della Cioppa, Hong, \& Craig, 2018).

\section{School-Based Bystander Interventions}

According to socio-ecological theory, behavior is influenced by the complex interaction of individual and environmental factors (Bronfenbrenner, 1979). For adolescents, the school serves as an important context for socioemotional adjustment as students spend a significant amount of time at school and in school-related activities (Eccles \& Roeser, 2011). Further, bullying is a group process that is maintained by group dynamics (Song \& Oh, 2017). Thus, within the socio-ecological model, the school is viewed as an environmental factor that interacts with the individual (i.e., student), and bullying occurs within a social context (i.e., peer) in which all students, including bystanders, have the potential to impact and be impacted by bullying. This model suggests that interventions may be most effective if they are based in the context of the school setting and include interventions that train bystanders how to intervene when they witness bullying.

Consistent with the socio-ecological theory, numerous studies support the efficacy of comprehensive, school-wide anti-bullying programs (Ttofi \& Farrington, 2011). Additionally, research on anti-bullying programs suggests that training bystanders to intervene is an important component of comprehensive, school-based bullying programs (Porter \& Smith-Adcock, 2017; Polanin, Espelage, \& Pigott, 2012). The majority of research examining bystander programs, however, focuses on the reduction of school-wide bullying rather than examining the impact of these interventions on the bystanders themselves (Janson et al., 2009). Additionally, bystander programs are generally embedded as components of comprehensive, school-wide programs that require significant time and resources for implementation (Menard \& Grotpeter, 2014). Further, the majority of bystander interventions have been developed for and normed on middle school or elementary school children (Denny et al., 2015). Because bullying at the high school level includes different types of bullying, including cyberbullying (Parris, Varjas, Meyers, \& Cutts, 2011), group bullying, and bullying in dating or romantic relationships (Pepler, et al., 2006), it is important for bullying programs for high school students to be developed specifically for this age group. 
This is an author-produced, peer-reviewed version of this article. The final, definitive version of this document can be found online at School Psychology International, published by SAGE. Copyright restrictions may apply. doi: 10.1177/0143034319830149

\section{The STAC Program}

The STAC program, which stands for "stealing the show," "turning it over," "accompanying others," and "coaching compassion," is a brief, stand-alone bystander program originally developed for elementary and middle schools students (Midgett, Doumas, Sears, Lundquist, \& Hausheer, 2015). STAC proram is based on social learning theory (Bandura, 1970) which suggests that individuals model behaviors when they perceive others as (a) influential, (b) receiving a reward rather than punishment for their behavior, and (c) similar in terms of personal characteristics. Because bullying occurs within the context of a peer-audience, how bystanders respond can influence the perpetrator (Salmivalli et al., 2011). A single adolescent student of high status, or a group of students who intervene to defend the target can shift attention and power away from the perpetrator (Salmivalli, 2014). As a result, when bystanders intervene, they can discontinue the reinforcement of perpetrators, model pro-social behavior, and provide social support for targets.

Following social learning theory, the STAC program was designed to train student leaders from different social groups to act as "defenders" (Midgett et al., 2015). Findings from studies conducted with elementary and middle school students indicate the STAC program is effective in increasing students' knowledge and confidence to intervene as “defenders" (-Midgett \& Doumas, 2016; Midgett et al, 2015; Midgett, Doumas, \& Trull, 2017; Midgett, Doumas, Trull, \& Johnston, 2017), a sense of personal responsibility (Midgett, Moody, Reilly, \& Lyter, 2017), as well in increasing self-esteem (Midgett, Moody et al., 2017; Midgett, Doumas, \& Trull, 2017) and decreasing anxiety ( Midgett, Doumas, Trull, \& Johnston, 2017) among students trained in the program.

More recently, the authors modified the STAC program to be appropriate for the high school level (Doumas, Midgett, \& Watts, 2018; Johnston, Midgett, Doumas, \& Moody, 2018; Midgett, Doumas, Johnston, Trull, \& Miller, 2018). Preliminary research on the "aged-up" STAC program indicated that the program was effective in increasing knowledge, confidence, and the use of the STAC strategies ( Doumas et al., 2018; Johnston et al., 2018), as well as awareness of bullying and a sense of personal responsibility to act (Johnston et al., 2018). Further, results from a randomized controlled study examining the efficacy of the modified STAC program on outcomes for bystanders indicated that high school students trained in the STAC program reported a decrease in depressive symptoms (Midgett \& Doumas, in press-a). The follow-up period, however, was short (i.e., 30 days) and the response rate for the sample was low (21\%). Further, the study outcomes were limited to depressive symptoms and gender differences were not examined, despite the research indicating gender differences in bystander distress (Brinkman \& Manning, 2016) and likelihood of intervening in bullying situations (Jenkins \& Nickerson, 2010; Oh \& Hazler, 2009; Trach et al., 2010).

\section{The Current Study}

The purpose of this study is to extend the literature by evaluating the efficacy of the STAC program on reducing internalizing symptoms among high school students trained to act as "defenders" when witnessing bullying behavior. We were also interested in examining gender as a moderator of intervention effects. To achieve this aim, high school students were randomized to one of two study conditions: (a) the STAC intervention and (b) an assessment-only control group. We hypothesized that participation in the intervention group would report a greater decrease in internalizing symptoms from baseline to a 3-month follow-up. We also hypothesized that gender would moderate these effects such that females in the intervention group would report the greatest reduction in internalizing symptoms.

\section{Methods}

\section{Research Design}

We used a randomized controlled trial design within one high school. We randomly assigned students to either the STAC intervention $(n=31)$ or an assessment-only control condition $(n=34)$. Participants completed baseline and 3month follow-up assessments. All study procedures were approved by the University Institutional Review Board and the School District Research Board.

\section{Participants}

Participants in the current study were students recruited from one urban high school in the Northwest United States (see Figure 1 for the participant flow diagram). Demographic information is provided in Table 1. Overall, 90.8\% ( $n$ $=59$ ) of the 65 participants ( $n=22$ male; $n=37$ female) completed both the baseline and 3-month follow-up 
This is an author-produced, peer-reviewed version of this article. The final, definitive version of this document can be found online at School Psychology International, published by SAGE. Copyright restrictions may apply. doi: 10.1177/0143034319830149

assessments. Chi-square analyses revealed no differences for gender, $\chi^{2}(1)=0.37, p=.54$, or ethnicity, $\chi^{2}(5)=1.98$, $p=.85$, between those who completed both assessments and those who did not. We did, however, find a significant difference for grade level, $\chi^{2}(1)=6.31, p=.04$, with a higher rates of attrition among $12^{\text {th }}$ grade students. There were no differences in the rate of attrition across the intervention and control groups, $\chi^{2}(1)=0.95, p=.33$.

\section{Procedure}

Members of the research team worked with the school counselor to conduct the study procedures. We used purposeful sampling to select students that teachers and school counselors perceived as high-status among diverse peer groups. After the students were selected, the school counselor briefly met with each student to discuss potential interest in the program. Interested students were sent home with an informed consent to be signed by a parent or guardian and returned to the school counselor. The school counselor followed up with a phone call or email to a parent or guardian when necessary. The school counselor then met students with parental consent to explain the research in more detail and collect student assent.

All participants completed baseline and 3-month follow-up assessments. After completing the baseline survey, the students in the intervention group completed a 90 -minute training program conducted by graduate students in a masters in counseling program. Students in the control group returned to their classrooms. Students in the intervention group also completed a brief questionnaire immediately after the 90-minute training to assess knowledge acquisition. Following the training, students in the intervention group participated in two, bi-weekly 15-minute small group booster sessions with counseling graduate students prior to the 3-month follow up. The reserchers provided all participants with a "pizza party" after conducting the 3-month follow-up asssesement.

\section{$\underline{\text { Measures }}$}

Demographic Survey. Students completed a brief demographic questionnaire that included questions about age, gender, and race/ethnicity.

Internalizing Symptoms. Internalizing symptoms were measured using items from the Depression and Anxiety Scale of the Behavioral Assessment Scale-3 Self Report of Personality-Adolescent Form (BASC-3 SRP-A; Reynolds \& Kamphaus, 2015). The Depression scale is comprised of 12 items measuring symptoms of depression, including feelings of unhappiness, sadness, and stress that may result in an inability to carry out everyday activities or may bring on thoughts of suicide (Reynolds \& Kamphaus, 2015). Five items are rated on a dichotomous scale, 0 (True) or 2 (False). Seven items are rated on a 4-point Likert Scale ranging from 0 (Never) to 3 (Almost Always). The Anxiety scale is comprised of 13 items assessing generalized fears, nervousness, and worries that typically are irrational and poorly defined (Reynolds \& Kamphaus, 2015). Three items are rated on a dichotomous scale of 0 (True) or 2 (False). Ten items are rated on a 4-point Likert Scale ranging from 0 (Never) to 3 (Almost Always). The BASC-3 SRP-A Depression and Anxiety scales have reliability coefficient alphas ranging in the .80s for males and females, and evidence of construct validity with correlations ranging from $.50-.97$ between the scales and other established measures of depression and anxiety (Reynolds \& Kamphaus, 2015). For this study, we used raw scores and combined the Depression and Anxiety scales $(\alpha=.91)$ to assess internalizing symptoms. The possible range of scores for the final internalizing scale was $0-67$.

To assess the levels of depression and anxiety in the current sample relative to normative data we converted minimum, maximum, and mean raw scores to T-scores using normative tables for males and female for $15-18$ year olds in the general population (BASC-3 SRP-A; Reynolds \& Kamphaus, 2015). For females, scores on the Depression scale ranged from $0-27(M=6.16, S D=6.76)$ and scores on the Anxiety scale $(M=15.93, S D=6.91)$ ranged from $5-$ 31 , which correspond to $\mathrm{T}$-scores ranging from $\mathrm{T}=40-81$ and $\mathrm{T}=39-72$, respectively. For males, scores on the Depression scale ranged from $0-11(M=2.72, S D=3.32)$ and scores on the Anxiety scale ranged from $0-21(M=$ 9.68, $S D=5.21$ ), which correspond to $\mathrm{T}$-scores ranging from $\mathrm{T}=41-62$ and $\mathrm{T}=34-66$, respectively. Interpretation of $T$-scores indicates female scores ranged from low $(T=31-40)$ to clinically significant $(T>70)$ and male scores ranged from low $(T=31-40)$ to at risk $(T=60-69)$. The mean score for the Depression and Anxiety scales for both females and males fell within the average range $(T=41-59)$. Thus, depression and anxiety scores for this sample were similar to the normative sample and ranged from low to clinically significant. 
This is an author-produced, peer-reviewed version of this article. The final, definitive version of this document can be found online at School Psychology International, published by SAGE. Copyright restrictions may apply. doi: 10.1177/0143034319830149

\section{The STAC Intervention}

The STAC intervention includes a 90-minute training that provides information about bullying and trains students in four STAC strategies (for details, see Midgett et al., 2015). The intervention also includes two 15-minute booster session that occur during the month following the training. These group sessions are intended to reinforce students' use of the strategies and brainstorm ways to become more effective "defenders." The STAC intervention was initially designed for middle and elementary school students and has been modified to be developmentally appropriate for the high school level (Doumas et al., 2018; Johnston et al., 2018; Midgett, Doumas, Johnston, Trull, \& Miller, 2018).

Didactic Component. The 90-minute didactic component of the training includes ice-breaker exercises, an audiovisual presentation, a video about bullying, and hands-on activities to engage students in the learning process. The didactic component is designed to teach students about (a) the complex nature of bullying in high school, including group bullying, (b) different types of bullying with a focus on cyberbullying and covert physical bullying, (c) characteristics of students who bully, including the likelihood they have been bullied themselves, (d) negative associated consequences of bullying for students who are targets, perpetrate bullying, and are bystanders, (e) bystander roles and the importance of acting as a "defender," and (f) the STAC strategies used for intervening in bullying situations. The four STAC strategies are described below.

"Stealing the Show." "Stealing the show" involves using humor or distraction to turn students' attention away from the bullying situation. Trainers teach bystanders to interrupt a bullying situation to displace the peer audience's attention away from the target and from the bullying situation so that other students do not join in or reinforce the bully.

"Turning it Over." "Turning it over" involves informing an adult about the situation and asking for help. During the training, students identify safe adults at school who can help. Students are taught to always "turn it over" in the case of overt physical bullying, cyberbullying, or if they are unsure as to how to intervene. Additionally, trainers discuss the importance of immediate documentation of social media posts that are intended to humiliate or hurt students. Students are taught how to document evidence of cyberbullying to report it to school authorities such as a student resource officer (SRO) or principal.

"Accompanying Others." "Accompanying others" involves the bystander reaching out to the student who was targeted to communicate that what happened is not acceptable, that the student who was targeted is not alone at school, and that the student bystander cares about them. Trainers teach students to approach a peer after they were targeted inviting them to spend time together. "Defenders" learn they can ask peers who were targeted if they would like to talk about what happened or "defenders" can implement this strategy indirectly by spending time with the student who was targeted communicating empathy and support.

"Coaching Compassion." "Coaching compassion” involves gently confronting the student who bullies either during or after a bullying incident to indicate that this type of behavior is unacceptable. Additionally, the bystander encourages the perpetrator to consider what it would feel like to be the target in the situation, thereby raising awareness and fostering empathy toward the target. Trainers teach bystanders to implement "coaching compassion" when they have an established relationship with the perpetrator or if the student who bullied is in a lower grade and bystanders believe they will be viewed as a higher-status peer.

Role-Plays. Trainers divide students into small groups to practice the STAC strategies. Role-plays include hypothetical bullying situations that students may encounter in high school. Example scenarios include: "Your friends are hanging out at your house after school, looking through Twitter. One friend decided to follow someone from school that they do not like, and then repost one of their posts to make fun of them. This is not the first time your friend has done something like this.”

Post-Training Booster Sessions. Two bi-weekly, 15-minute booster session occur after the training. During these meetings, students discuss which strategies they used and whether or not the strategies seemed to be effective. Trainers answer questions and facilitate brainstorming effective ways to implement the STAC strategies, to use more than one strategy to intervene, and, when appropriate, to work as a team to intervene during or after a bullying incident. 
This is an author-produced, peer-reviewed version of this article. The final, definitive version of this document can be found online at School Psychology International, published by SAGE. Copyright restrictions may apply. doi: 10.1177/0143034319830149

\section{Intervention Fidelity}

The researchers created a STAC training video to train all graduates student involved in the project to conduct the STAC program. All trainers watched the video prior to conducting the STAC intervention. The second author was also present at the 90 -minute training to ensure it was accurately delivered. The second author rated the training on a dichotomous scale, Yes or No, to evaluate whether presenters accurately taught the definition and types of bullying, the STAC strategies, and whether they deviated from training materials. Furthermore, the researchers evaluated if student trainers conducted all role-plays included in the training. Of the two presenters conducting the training, $100 \%$ accurately taught the definition and types of bullying and the STAC strategies, there was $100 \%$ adherence to the training materials, and presenters conducted all four role-plays in $100 \%$ of the trainings. Additionally, the researchers develped a standard set of scripted questions used for the 2, 15-minute booster sessions. As an additional measure of intervention fidelity, we examined changes in knowledge and confidence from pre-training to immediate post-training to determine if students in the intervention group learned the information. Results indicated a significant increase in knowledge and confidence from baseline $(M=35.09, S D=4.75)$ to immediate post-training, $(M=42.00, S D=2.75)$, $t(30)=-8.78, p<.001$, Cohen's $d=1.81$.

\section{Data Analysis}

Prior to analysis, the internalizing symptoms outcome variable was examined for outliers and normality at baseline and follow-up assessments. We found no outliers and skew and kurtosis were within normal range. We confirmed that students in the intervention and control groups were equivalent with respect to demographics and the baseline outcome with $t$-tests for continuous variables and chi-square tests for categorical variables. We used general linear model (GLM) repeated measures analysis of variance (ANOVA) to examine the intervention effects across time and gender as a moderator of intervention effects across time for the outcome variable. The three fixed effects were Time (baseline; follow-up), Group (intervention; control), and Gender (male; female). Post-hoc GLM repeated measures ANOVAs were conducted separately for males and females to determine the nature of the significant 3-way interactions. Simple slopes were also plotted to examine the direction and degree of significant interactions testing moderator effects (Aiken \& West, 1991). We calculated effect size using partial eta squared ( $\eta^{2}$ p) for ANOVA analyses, with .01 considered small, .06 considered medium, and .14 considered large (Cohen, 1969; Richardson, 2011). Analyses were considered significant at $p<.05$ and were conducted in SPSS version 24.0. We controlled for Type 1 error by using the Holm-Bonferroni procedure (Holm, 1979).

\section{Results}

Descriptive statistics for the outcome variable by group and gender are presented Table 2. Results revealed a significant interaction effect for Time x Group x Gender, Wilks’ Lambda $=.93, F(1,55)=4.10, M S E=27.93, p=$ $.05, \eta_{p}^{2}=.07$, indicating gender moderated intervention effects. The main effect for Time, Wilks' Lambda $=.98, F(1$, $55)=1.07, M S E=27.93, p=.31, \eta_{p}^{2}=.02$, the interaction effect for Time $\mathrm{x}$ Group, Wilks’ Lambda $=.96, F(1,55)=$ 2.04, $M S E=27.93, p=.16, \eta_{p}^{2}=.04$, and the interaction effect for Time $\mathrm{x}$ Gender, Wilks’ Lambda $=.99, F(1,55)=$ $0.09, M S E=27.93, p=.76, \eta_{p}^{2}=.00$, were not significant.

Follow-up analyses indicated a significant Time $x$ Group interaction for female students from baseline to the 3-month follow-up, Wilks' Lambda $=.85, F(1,35)=6.13, M S E=39.77, p=.02, \eta^{2}{ }_{p}=.15$. The main effect for Time was not significant, Wilks’ Lambda $=.98, F(1,20)=0.92, M S E=39.77, p=.35, \eta^{2} p=.03$. For male students, neither the main effect for Time, Wilks' Lambda $=.96, F(1,20)=0.79, M S E=7.21, p=.39, \eta^{2} p=.04$, nor interaction effect for Time x Group, Wilks’ Lambda $=.98, F(1,20)=0.53, M S E=7.21, p=.48, \eta^{2}=.03$, were significant. As seen in Figure 2, female students in the intervention group reported a decrease in internalizing symptoms at the 3-month follow-up assessment relative to female students in the control group.

\section{Discussion}

The purpose of this study was to evaluate the efficacy of a brief, bystander intervention on decreasing internalizing symptoms among high school students. Although witnessing bullying is associated with internalizing symptoms ( Hutchinson, 2012; Janson et al., 2009; Midgett \& Doumas, in press-b; Rivers \& Noret, 2010; 2013; Rivers et al., 2009), there is a limited amount of research examining interventions to address negative consequences among student bystanders (Janson et al., 2009). Results of this study provided support for the efficacy of the STAC intervention in 
This is an author-produced, peer-reviewed version of this article. The final, definitive version of this document can be found online at School Psychology International, published by SAGE. Copyright restrictions may apply. doi: 10.1177/0143034319830149

decreasing internalizing symptoms among female high school students. Female students who participated in the STAC intervention reported a decrease in internalizing symptoms compared to female students in the control condition. In contrast, there were no differences in internalizing symptoms between the two groups for male students.

Results of this study are consistent with the literature suggesting that when bystanders are trained to act as "defenders" as part of a school-wide intervention they experience reductions in internalizing symptoms (Williford, Boulton, Noland, Little, Karna, \& Salmivalli, 2012). Findings are also consistent with prior research that indicates brief bystander interventions can improve positive socio-emotional outcomes among bystanders in elementary ( Midgett, Doumas, \& Trull, 2017) and middle (Midgett, Doumas, Trull, \& Johnston, 2017) school, as well as depressive symptoms among high school students (Midgett \& Doumas, in press-a). This study adds to the literature on using bystander interventions to improve bystander outcomes, demonstrating the efficacy of a brief, bystander intervention in reducing internalizing symptoms among female high school students over a 3-month follow-up period. Identifying interventions for student bystanders in high school is particularly important as witnessing bullying in high school is associated with internalizing symptoms including depressive symptoms (Hutchinson, 2012; Janson et al., 2009; Rivers et al., 2009), anxiety (Rivers et al., 2009), and suicidal ideation (Rivers \& Noret, 2010; 2013).

Although findings supported the efficacy of the STAC intervention in reducing internalizing symptoms for female students, there were no significant effects for males. One explanation for this finding is that females experience more distress than males when witnessing bullying (Brinkman \& Manning, 2016). In this study, at baseline, female students reported higher levels of internalizing symptoms $(M=22.27, S D=11.91)$ than males $(M=13.00, S D=7.60)$. Our finding that there was no group difference in internalizing symptoms among male students may be related to male students experiencing lower levels of distress. Alternatively, gender differences in intervention effects may be related to differential responses to the intervention. Specifically, research indicates females are more likely to intervene in bullying situations than males (Jenkins \& Nickerson, 2017; Oh \& Hazler, 2009; Trach et al., 2010) perhaps due to higher a higher likelihood of noticing bullying events (Jenkins \& Nickerson, 2017) and higher levels of confidence to intervene (Brinkman \& Manning, 2016). Thus, the gender differences found in this study may be related to differences in frequency of observing and intervening in bullying situations.

\section{Limitations and Directions for Future Research}

While this study extends the literature investigating a brief, bullying bystander intervention specifically designed for high school students, certain limitations should be considered. First, generalizability of the results is limited due to the single high school in the United States with a predominantly White student body. Because there are substantial variations in rates and types of bullying across countries (Bradshaw, Crous, Rees, \& Turner, 2017), it is not clear that results of this study are generalizable beyond the United States. However, research conducted in Asia, Europe, Australia, and the United States indicates that bystanders' responses to witnessing bullying are similar cross-culturally (see Song \& Oh, 2017). Additionally, research conducted in the United Kingdom, Canada, and Taiwan suggests that bystanders experience mental health risks similar to those in the United States, including internalizing problems (e.g., Rivers et al., 2009; Lambe, Hudson, Craig, \& Pepler, 2017; Wu, Luu, \& Luh, 2016). Research from Finland also demonstrates the efficacy of a school-wide anti-bullying programs that includes a bystander component in reducing internalizing problems among students (Williford et al., 2012). Future research with larger and more diverse samples, including international samples, however, is needed to increase generalizability of the results of the current study. Additionally, we found differential rates of attrition by grade level, with a high rate of attrition among $12^{\text {th }}$ grade students. It is unclear why we retained more $10^{\text {th }}$ and $11^{\text {th }}$ grade students than seniors. Future research is needed to further explore differential rates of attrition by grade level if that finding is replicated.

Although the current study provides support for the impact of the STAC intervention on internalizing symptoms among bystanders, the outcome was limited to self-reported symptoms of depression and anxiety. In future studies, researchers should examine additional symptoms (i.e., somatic complaints) and incorporate teacher and/or parent measures in addition to student measures. Additionally, although this study demonstrated that gender moderated intervention effects, we did not examine the process by which the intervention impacted internalizing symptoms among females. Future research should examine possible mediators of intervention effects including awareness of bullying incidents, confidence in intervening, and changes in actual bystander behaviors. 
This is an author-produced, peer-reviewed version of this article. The final, definitive version of this document can be found online at School Psychology International, published by SAGE. Copyright restrictions may apply. doi: 10.1177/0143034319830149

\section{Implications for School Psychologists}

This study has several practical implications for school psychologists. First, findings support the efficacy of the STAC program on decreasing negative consequences associated with witnessing bullying as a bystander. Although school psychologists may be aware of the negative impact of bullying on targets, they may not know that witnessing bullying is associated with consequences for bystanders. Because being a bystander is associated with depressive symptoms (Hutchinson, 2012; Janson et al., 2009; Rivers et al., 2009), anxiety (Rivers et al., 2009), and suicidal ideation (Rivers \& Noret, 2010; 2013), supporting programming that teaches bystanders to act as "defenders" is an important objective for high school psychologists. Providing school-wide training may be most beneficial, as the majority of students report witnessing bullying as a bystander (Bradshaw et al., 2007). Additionally, because stand-alone bystander interventions may also reduce bullying (Midgett, Doumas, \& Johnston, 2018; Midgett, Doumas, Trull, \& Johnson, 2017), training the student body may not only improve outcomes for bystanders, but may also reduce bullying schoolwide. School psychologists may also provide psychoeducational groups for adolescents who witness bullying, with education, role-plays, and feedback occurring within the group context.

This study also has important implications for gender-based interventions for bystanders. Research conducted in the United States and Sweden indicates female students are naturally more likely to notice bullying (Jenkins \& Nickerson, 2017), have greater moral sensitivity to bullying (i.e., recognizing harm to the target and sympathizing with the target) (Thornberg \& Jungert, 2013), and have higher levels of confidence to intervene (Brinkman \& Manning, 2016) than male students. Thus, bystander programs focusing on providing specific skills to intervene as a "defender" may be particularly beneficial to female students. In contrast, interventions for male students may need to focus on helping male students become more aware of bullying and the importance of intervening to support targets of bullying. Male students may benefit from more in depth information on how to identify different types of bullying to increase awareness. Providing information on the impact of bullying on students who are targeted may also be important to foster empathy for targets and increase a sense of responsibility to intervene. Training male students to use specific skills to intervene as "defenders" may be more effective once they become more aware of bullying and the importance of intervening.

\section{Conclusion}

School bullying is an international problem with similarities cross-nationally in how bystanders respond to bullying behavior (Song \& Oh, 2017). Although there are a handful of international programs that address bullying with a comprehensive, school-wide strategy that includes a bystander component (e.g., Kiva; Salmivalli et al., 2011), programs developed for high school students are limited. Additionally, not all schools have the resources to provide comprehensive, school-wide programs. Stand-alone bullying bystander programs, such as the one investigated in this

study, can be adopted by schools with few resources. The STAC program has the potential to reduce internalizing symptoms for female students who witness bullying, as well as to reduce bullying through bystander intervention.

\section{Acknowledgements}

We would like to thank Jenifer Ayres for her assistance with participant recruitment and data collection.

\section{Conflict of Interest Disclosure}

Boise State University has entered into an agreement with the second author (Aida Midgett) under which Aida Midgett will receive a share of the royalties related to sales of the STAC program. 
This is an author-produced, peer-reviewed version of this article. The final, definitive version of this document can be found online at School Psychology International, published by SAGE. Copyright restrictions may apply. doi: 10.1177/0143034319830149

\section{References}

Aiken, L. S. \& West, S. G. (1991). Multiple regression: Testing and interpreting interactions. Sage.

Bradshaw, C.P., Sawyer, A.L., \& O’Brennan, L.M. (2007). Bullying and peer victimization at school: Perceptual differences between students and school staff. School Psychology Review, 36, 361-382.

Brinkman, B. G., \& Manning, L. (2016). Children's intended responses to gender-based bullying as targets and bystanders. Childhood, 23, 221-235. doi:10.1177/0907568215595095

Bronfenbrenner, U. (1979). Contexts of child rearing: Problems and prospects. American Psychologist, 34, 844.

Chen, L. M., Chang, L. Y., \& Cheng, Y. Y. (2016). Choosing to be a defender or an outsider in a school bullying incident: Determining factors and the defending process. School Psychology International, 37, 289-302. doi:10.1177/0143034316632282

Choi, S., \& Cho, Y. I. (2013). Influence of psychological and social factors on bystanders' roles in school bullying among Korean-American students in the United States. School Psychology International, 34, 67-81. doi:10.1177/0143034311430406

Cohen, J. (1969). Statistical power analysis for the behavioural sciences. New York: Academic Press.

Denny, S., Peterson, E. R., Stuart, J., Utter, J., Bullen, P., Fleming, T., . . Milfont, T. (2015). Bystander intervention, bullying, and victimization: A multilevel analysis of New Zealand high schools. Journal of School Violence, 14, 245-272. doi:10.1080/15388220.2014.910470

Doumas, D. M., Midgett, A., \& Watts, A. D. (2018). A pilot evaluation of the developmental validity of a bullying bystander program adapted for high school students. Manuscript submitted for publication.

Eccles, J. S., \& Roeser, R. W. (2011). Schools as developmental contexts during adolescence. Journal of Research on Adolescence, 21, 225-241. doi: 10.1111/j.1532-7795.2010.00725.x

Forsberg, C., Samuelsson, M., \& Thornberg, R. (2014). Bystanders to bullying: Fourth- to seventh-grade students' perspectives on their reactions. Research Papers in Education, 29, 557-576. doi:10.1080/02671522.2013.878375

Hawkins, D. L., Pepler, D. J., \& Craig, W. M. (2001). Naturalistic observations of peer interventions in bullying. Social Development, 10, 512-527. doi:10.1111/1467-9507.00178

Holm, S. (1979). A simple sequentially rejective multiple test procedure. Scandinavian Journal of Statistics, 65-70.

Hutchinson, M. (2012). Exploring the impact of bullying on young bystanders. Educational Psychology in Practice, 28, 425-442. doi:10.1080/02667363.2012.727785

Jenkins, L. N., \& Nickerson, A. B. (2017). Bystander intervention in bullying: Role of social skills and gender. The Journal of Early Adolescence. doi:10.1177/0272431617735652

Johnston, A., Midgett, A., Doumas, D. M., \& Moody, S. (2018). A mixed methods evaluation of the "aged-up" STAC bullying bystander intervention for high school students. The Professional Counselor, 8, 73-87. doi:10.15241/adj.8.1.73

Lambe, L. J., Della Cioppa, V., Hong, I. K., \& Craig, W. M. (2018). Standing up to bullying: A social ecological review of peer defending in offline and online contexts. Aggression and Violent Behavior. doi:10.1016/j.avb.2018.05.007

Lambe, L. J., Hudson, C. C., Craig, W. M., \& Pepler, D. J. (2017). Does defending come with a cost? Examining the psychosocial correlates of defending behaviour among bystanders of bullying in a Canadian sample. Child Abuse \& Neglect, 65, 112-123. doi: 10.1016/j.chiabu.2017.01.012

Menard, S., \& Grotpeter, J. K. (2014). Evaluation of bully-proofing your school as an elementary school antibullying intervention. Journal of School Violence, 13, 188-209. doi:10.1080/15388220.2013.840641

Midgett, A., \& Doumas, D. M. (in press-a). The impact of a brief, bullying bystander intervention on depressive symptoms. Journal of Counseling and Development.

Midgett, A., \& Doumas, D. M. (in press-b). Witnessing bullying at school: The association between being a bystander and anxiety and depressive symptoms. School Mental Health.

Midgett, A., \& Doumas, D. M. (2016). Training elementary students to intervene as peer-advocates to stop bullying at school: A pilot study. Journal of Creativity in Mental

Health, 11, 353-365. doi:10.1080/15401383.2016.1164645

Midgett, A., Doumas, D. M., \& Johnston, A. (2018). Establishing school counselors as leaders in bullying curriculum delivery: Evaluation of a brief, school-wide bystander intervention. Professional School Counseling, 21, 1-9. doi:10.1177/2156759X18778781

Midgett, A., Doumas, D. M., Johnston, A., Trull, R., \& Miller, R. (2018). Re-thinking bullying interventions for high school students: A qualitative study. Journal of Child and Adolescent Counseling, 4, 146-163. doi:10.1080/23727810.2017.1381932 
This is an author-produced, peer-reviewed version of this article. The final, definitive version of this document can be found online at School Psychology International, published by SAGE. Copyright restrictions may apply. doi: 10.1177/0143034319830149

Midgett, A., Doumas, D. M., Sears, D., Lunquist, A., \& Hausheer, R. (2015). A bystander bullying psychoeducation program with middle school students: A preliminary report. The Professional Counselor, 5, 486-500. doi:10.15241/am.5.4.486

Midgett, A., Doumas, D. M., \& Trull, R. (2017). Evaluation of a brief, school-based bullying bystander intervention for elementary school students. Professional School Counseling, 20, 172-183. doi:10.5330/1096-240920.1.172

Midgett, A., Doumas, D. M., Trull, R., \& Johnson, J. (2017). Training students who occasionally bully to be peer advocates: Can a brief bystander intervention decrease bullying behavior? Journal of Child and Adolescent Counseling, 3, 1-13. doi:10.1080/23727810.2016.1277116

Midgett, A., Doumas, D. M., Trull, R., \& Johnston, A. (2017). A randomized controlled study evaluating a brief, bystander bullying intervention with junior high school students.

Journal of School Counseling, 15(9). Retrieved from http://www.jsc.montana.edu/articles/v15n9.pdf

Midgett, A., Moody, S. J., Reilly, B., \& Lyter, S. (2017). The phenomenological experience of student-advocates trained as defenders to stop school bullying. The Journal of Humanistic Counseling, 56, 53-71. doi:10.1002/johc.120

O'Connell, P., Pepler, D., \& Craig, W. (1999). Peer involvement in bullying: Insights and challenges for intervention. Journal of Adolescence, 22, 437-452. doi:10.1006/jado.1999.0238

Oh, I., \& Hazler, R. J. (2009). Contributions of personal and situational factors to bystanders' reactions to school bullying. School Psychology International, 30, 291-310. doi:10.1177/0143034309106499

Padgett, S., \& Notar, C. E. (2013). Bystanders are the key to stopping bullying. Universal Journal of Educational Research, 1, 33-41. doi:10.13189/ujer.2013.010201

Parris, L., Varjas, K., Meyers, J., \& Cutts, H. (2011). High school students’ perceptions of coping with cyberbullying. Youth \& Society, 44, 1-23. doi:10.1177/0044118XII39888I

Pepler, D. J., Craig, W. M., Connolly, J. A., Yuile, A., McMaster, L., \& Jiang, D. (2006). A developmental perspective on bullying. Aggressive Behavior, 32, 376-384. doi:10.1002/ab.20136

Polanin, J. R., Espelage, D. L., \& Pigott, T. D. (2012). A meta-analysis of school-based bullying prevention programs' effects on bystander intervention behavior. School Psychology Review, 41, 47-65.

Porter, J. R. \& Smith-Adcock, S. (2017). Children's tendency to defend victims of school bullying. Professional School Counseling, 20,1-13. doi: 10.5330/1096-2409-20.1.1

Reynolds, C. R., Kamphaus, R. W., \& Vannest, K. J. (2015). BASC3: Behavior Assessment System for Children. PscyhCorp.

Richardson, J. T. E. (2011). Eta squared and partial eta squared as measurements of effect size in educational research. Educational Research Review, 6, 135-147. doi:10.1016/j.edurev.2010.12.001

Rigby, K., \& Johnson, B. (2006). Expressed readiness of Australian schoolchildren to act as bystanders in support of children who are being bullied. Educational psychology, 26, 425-440.

doi:10.1080/01443410500342047Rivers, I., Poteat, V. P., Noret, N., \& Ashurst, N. (2009). Observing bullying at school: The mental health implications of witness status. School Psychology Quarterly, 24, 211223. doi:10.1037/a0018164

Rivers, I., \& Noret, N. (2010). Participant roles in bullying behavior and their association with thoughts of ending one's life. Crisis, 31, 143-148. doi:10.1027/0227-5910/a000020

Rivers, I., \& Noret, N. (2013). Potential suicide ideation and its association with observing bullying at school. Journal of Adolescent Health, 53, 32-36. doi:10.1016/j.jadohealth.2012.10.279

Salmivalli, C. (2014). Participant roles in bullying: How can peer bystanders be utilized in interventions? Theory into Practice, 53, 286-292. doi:10.1080/00405841.2014.947222

Salmivalli, C., Lagerspet, K., Björkqvist, K., Österman, K., \& Kaukiainen, A. (1996). Bullying as a group process: Participant roles and their relations to social status within the group. Aggressive Behavior, 22, 1-15. doi:10.1002/(SICI)1098-2337(1996)22:13.0.CO;2-T

Salmivalli, C., \& Voeten, M. (2004). Connections between attitudes, group norms, and behaviour in bullying situations. International Journal of Behavioral Development, 28(3), 246-258. doi:10.1080/01650250344000488

Salmivalli, C., Voeten, M., \& Poskiparta, E. (2011). Bystanders matter: Associations between reinforcing, defending, and the frequency of bullying behavior in classrooms. Journal of Clinical Child \& Adolescent Psychology, 40, 668-676. doi:10.1080/15374416.2011.597090

Song, J., \& Oh, I. (2017). Investigation of the bystander effect in school bullying: Comparison of experiential, psychological and situational factors. School Psychology International, 38, 319-336. doi:10.1177/0143034317699997 
This is an author-produced, peer-reviewed version of this article. The final, definitive version of this document can be found online at School Psychology International, published by SAGE. Copyright restrictions may apply. doi: 10.1177/0143034319830149

Thornberg, R., \& Jungert, T. (2013). Bystander behavior in bullying situations: Basic moral sensitivity, moral disengagement and defender self-efficacy. Journal of Adolescence, 36, 475-483. doi:10.1016/j.adolescence.2013.02.003

Thornberg, R., Landgren, L., \& Wiman, E. (2018). 'It Depends': A qualitative study on how adolescent students explain bystander intervention and non-intervention in bullying situations. School Psychology International. doi:10.1177/0143034318779225

Trach, J., Hymel, S., Waterhouse, T., \& Neale, K. (2010). Bystander responses to school bullying: A cross-sectional investigation of grade and sex differences. Canadian Journal of School Psychology, 25, 114-130. doi:10.1177/0829573509357553

Ttofi, M. M., \& Farrington, D. P. (2011). Effectiveness of school-based programs to reduce bullying: A systematic and meta-analytic review. Journal of Experimental Criminology, 7, 27-56. doi:10.1007/s11292-010-9109-1

U.S. Department of Education: National Center for Educational Statistics. (2016). Student reports of bullying: Results from the 2015 school crime supplement to the national crime victimization survey (NCES 2017015). Retrieved from https://nces.ed.gov/pubs2017/2017015.pdf

Waasdorp, T. E., Pas, E. T., Zablotsky, B., \& Bradshaw, C. P. (2017). Ten-year trends in bullying and related attitudes among 4th-to 12th-graders. Pediatrics, e20162615

Williford, A., Boulton, A., Noland, B., Little, T. D., Karna, A., \& Salmivalli, C. (2012). Effects of the KiVa antibullying program on adolescents' depression, anxiety and perception of peers. Journal of Abnormal Child Psychology, 40, 289-300. doi:10.1007/s10802-011-9551-1Wu, W. C., Luu, S., \& Luh, D. L. (2016). Defending behaviors, bullying roles, and their associations with mental health in junior high school students: A population-based study. BMC Public Health, 16, 1066. doi:10.1186/s12889-016-3721-6 
This is an author-produced, peer-reviewed version of this article. The final, definitive version of this document can be found online at School Psychology International, published by SAGE. Copyright restrictions may apply. doi: 10.1177/0143034319830149

Table 1

Sample Characteristics by Study Group

Control Group $\quad$ Intervention Group $\quad$ Total Sample

$\begin{array}{llll}\text { Characteristics } & (\mathrm{n}=34) & (\mathrm{n}=31) & (\mathrm{n}=65)\end{array}$

Age in years, $M(S D)$

Gender

Male

Female

Race/Ethnicity

White

Hispanic

Asian-American

African-American

Pacific Islander

Other
$47.1 \%$

$52.9 \%$

$76.5 \%$

$11.8 \%$

$0.0 \%$

$5.9 \%$

$2.9 \%$

$2.9 \%$
$29.0 \%$

$71.0 \%$
$61.5 \%$

$38.5 \%$ 
This is an author-produced, peer-reviewed version of this article. The final, definitive version of this document can be found online at School Psychology International, published by SAGE. Copyright restrictions may apply. doi: 10.1177/0143034319830149

\section{Table 2}

Means and Standard Deviations for Internalizing Symptoms by Study Condition and Gender

\section{Gender}

Female $^{\mathrm{a}} \quad$ Male $^{\mathrm{b}} \quad$ Total $^{\mathrm{c}}$

\begin{tabular}{lllll} 
Control & Baseline & $20.06(11.04)$ & $14.80(7.99)$ & $17.59(9.94)$ \\
\cline { 2 - 4 } Intervention & 3-Month Follow-Up & $22.29(15.27)$ & $13.40(8.94)$ & $18.13(13.30)$ \\
& Baseline & $24.15(12.57)$ & $9.14(5.27)$ & $20.26(12.91)$ \\
& 3-Month Follow-Up & $19.10(10.92)$ & $9.00(7.10)$ & $16.48(10.91)$
\end{tabular}

a Control Group $n=17$; Intervention Group $n=20$

${ }^{\mathrm{b}}$ Control Group $n=15$; Intervention Group $n=7$.

${ }^{\text {c }}$ Control Group $n=32$; Intervention Group $n=27$. 
This is an author-produced, peer-reviewed version of this article. The final, definitive version of this document can be found online at School Psychology International, published by SAGE. Copyright restrictions may apply. doi: 10.1177/0143034319830149

\section{Figure 1}

Participant flow diagram

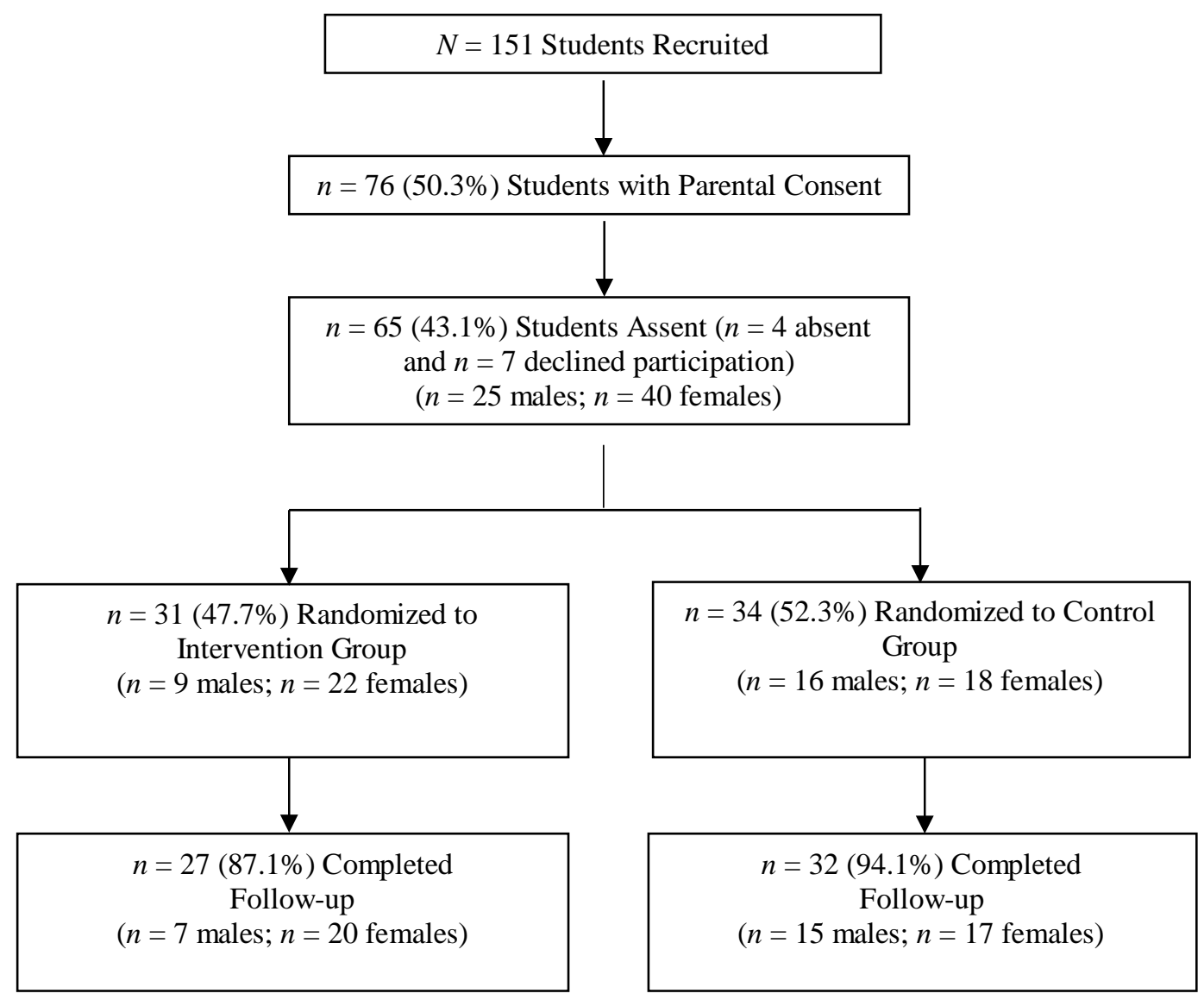


This is an author-produced, peer-reviewed version of this article. The final, definitive version of this document can be found online at School Psychology International, published by SAGE. Copyright restrictions may apply. doi: 10.1177/0143034319830149

\section{Figure 2}

Means for baseline and 3-month follow-up for internalizing symptoms by group and gender

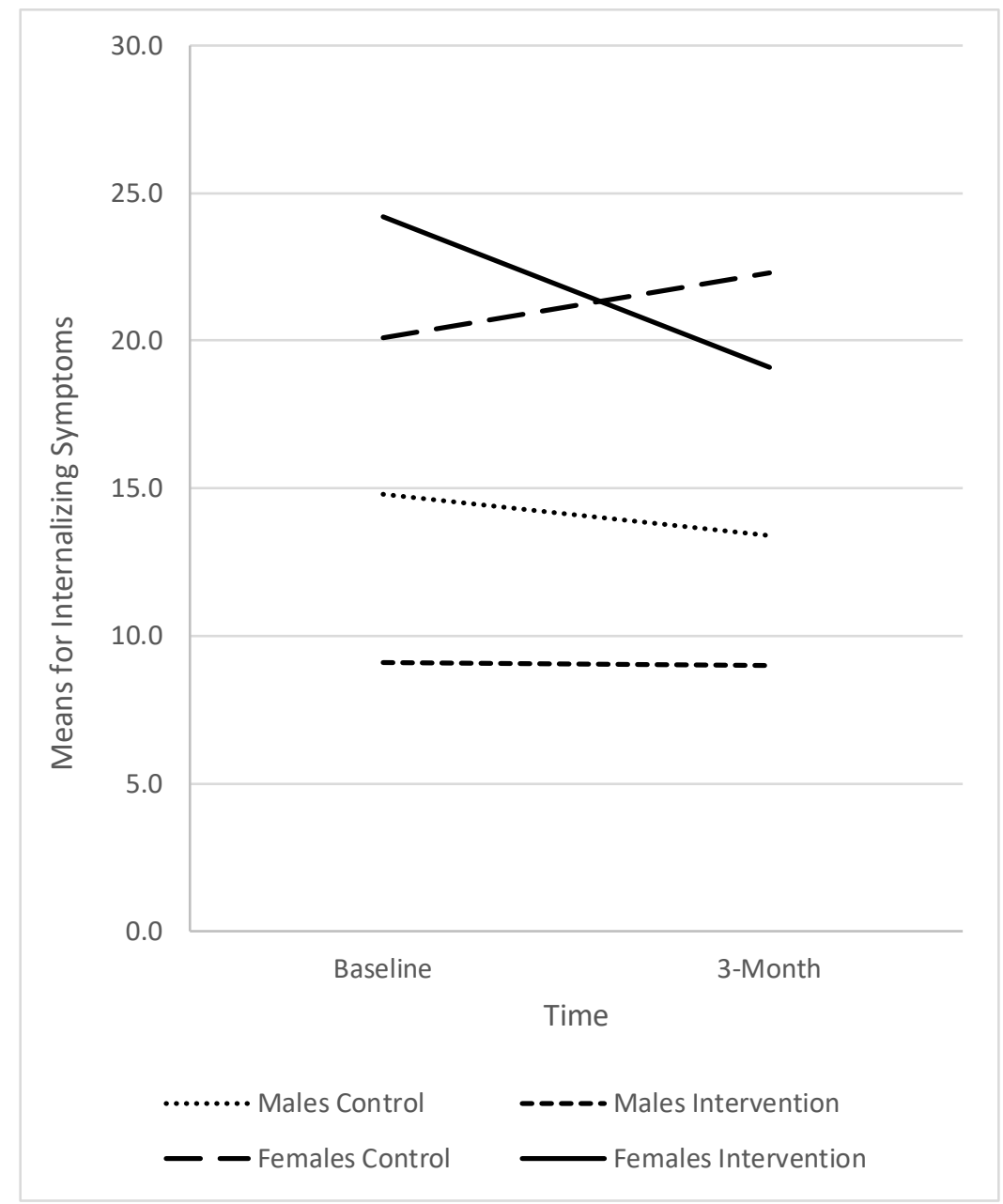

